\title{
A Cell Culture Model that Mimics Physiological Tissue Oxygenation Using Oxygen-permeable Membranes
}

\author{
Chloe-Anne Martinez, Peter A. Cistulli and Kristina M. Cook*
}

The University of Sydney, Charles Perkins Centre, Northern Clinical School, New South Wales, Australia *For correspondence: kristina.cook@sydney.edu.au

\begin{abstract}
[Abstract] Dissolved oxygen and its availability to cells in culture is an overlooked variable which can have significant consequences on experimental research outcomes, including reproducibility. Oxygen sensing pathways play key roles in cell growth and behavior and pericellular oxygen levels should be controlled when establishing in vitro models. Standard cell culture techniques do not have adequate control over pericellular oxygen levels. Slow diffusion through culture media limits the precision of oxygen delivery to cells, making it difficult to accurately reproduce in vivo-like oxygen conditions. Furthermore, different types of cells consume oxygen at varying rates and this can be affected by the density of growing cells. Here, we describe a novel in vitro system that utilizes hypoxic chambers and oxygen-permeable culture dishes to control pericellular oxygen levels and provide rapid oxygen delivery to adherent cells. This procedure is particularly relevant for protocols studying effects of rapid oxygen changes or intermittent hypoxia on cellular behavior. The system is inexpensive and easily assembled without highly specialized equipment.
\end{abstract}

Keywords: Cell culture, Oxygen, Tissue oxygenation, Normoxia, Hypoxia

[Background] Oxygen availability can impact on many signaling pathways and small changes to the level of pericellular oxygen can alter growth rate, metabolism, free radical production, and general cell behavior (Place et al., 2017; Bordt, 2018). Therefore, to preserve normal cellular function, oxygen levels need to be maintained within a relatively narrow 'normoxic' range. This applies both to cells in vivo and to cell lines used in cell culture (Hunyor and Cook, 2018).

In most cell culture models, experimental 'normoxic' values are based on the oxygen levels supplied in cell culture incubators. In dry air at sea level, atmospheric oxygen is $\sim 20.9 \% \mathrm{v} / \mathrm{v}$ (Hunyor and Cook, 2018). In standard humidified cell culture incubators maintained at $5 \% \mathrm{CO}_{2}$, oxygen levels are equal to $18.6 \% \mathrm{O}_{2}(\mathrm{v} / \mathrm{v})$, equivalent to an oxygen tension or oxygen partial pressure $\left(\mathrm{pO}_{2}\right)$ of $138 \mathrm{mmHg}($ Wenger et al., 2015). However, cells are maintained at much lower $\mathrm{pO}_{2}$ levels in vivo (Carreau et al., 2011). Under normal ventilatory conditions, $\mathrm{pO}_{2}$ in the arterial blood ranges from $80-100 \mathrm{mmHg}(10.8-13.5 \%$ $\mathrm{O}_{2} \mathrm{v} / \mathrm{v}$ ) and this is further lowered as oxygen molecules diffuse through tissue and are consumed by cells (Carreau et al., 2011). Moreover, different tissues have unique ranges of physiological normoxia, depending on the specific oxygen demands of individual tissues. Using a single oxygen concentration to represent physiological normoxia for a range of cell types is not representative of the in vivo environment (Carreau et al., 2011). When studying pathological oxygen conditions (such as in ischemia or in tumor hypoxia) cells should be exposed to oxygen tensions that appropriately model the specific 
pathological state of the tissue. In brain ischemia, $\mathrm{pO}_{2}$ levels can decrease below $10 \mathrm{mmHg}(1 \% \mathrm{v} / \mathrm{v})$ (Hoffman et al., 1999). In tumors, $\mathrm{pO}_{2}$ levels can range from $15 \mathrm{mmHg}(2.1 \% \mathrm{v} / \mathrm{v})$ to as low as $2 \mathrm{mmHg}$ $(0.3 \% \mathrm{v} / \mathrm{v})$ and this can also depend on the tissue of origin (Byrne et al., 2014).

The concentration of oxygen used to represent hypoxia is important because oxygen-sensing proteins have optimal $\mathrm{pO}_{2}$ ranges for which they operate. Hypoxia inducible factor (HIF) is a transcription factor activated by low oxygen. HIF is thought to control the expression of up to 1,000 genes and it has important roles in health and disease including embryogenesis (Dunwoodie, 2009), angiogenesis (Cook and Figg, 2010), cancer (Cook et al., 2009), diabetes (Thangarajah et al., 2010), inflammation and immune function (Palazon et al., 2014). HIF-1 $\alpha$ and HIF-2 $\alpha$ have been found to be stabilized under different oxygen tensions (Holmquist-Mengelbier et al., 2006; Lin et al., 2011). In neuroblastoma, HIF$2 \alpha$ is stabilized in $5 \% \mathrm{O}_{2}$ and can be strongly expressed even in well-vascularized areas, while HIF-1 $\alpha$ is stabilized below $1 \% \mathrm{O}_{2}$ in extremely hypoxic regions of the tumor (Holmquist-Mengelbier et al., 2006). A small change in oxygen levels can therefore alter the balance of HIF-1 $\alpha$ and HIF-2 $\alpha$, which affects what genes are expressed and ultimately how the cells behave. As we build better in vitro systems to accurately model in vivo conditions, oxygen levels are a key experimental variable to consider.

A common method used to modulate oxygen conditions in cell culture involves the use of a $\mathrm{CO}_{2}$ incubator with variable oxygen control (Wu and Yotnda, 2011). The major drawback of this method when using traditional cell culture techniques is that long exposure periods are required for the oxygen present in the gas phase to diffuse to cells attached at the bottom of the culture dish. Depending on the volume and depth of media, this can take hours due to poor oxygen diffusivity in aqueous media (Allen et al., 2001). Oxygen conditions at the pericellular level therefore do not immediately match the oxygen conditions supplied in the incubator air. One method to counteract this is to pre-equilibrate media/reagents to the desired $\mathrm{pO}_{2}$ levels prior to culturing. The major issue with this is that unless the cell culture is handled within a closed compartment (such as in an airtight glove box), oxygen from the ambient air is constantly diffusing into media and reagents, preventing the precise control over the oxygen concentrations being delivered to cells (Byrne et al., 2014). Many laboratories are not readily equipped with oxygen-controlled incubators or glove boxes due to their high costs.

As a more cost-effective alternative, we have designed a cell culture system that utilizes commercially available oxygen-permeable cultureware. The culture dishes are composed of a thin membrane surface that is highly permeable to oxygen. Cells adhere to the membrane and are covered in media as with normal cell culture methods. However, due to the extremely high oxygen permeability of the membranes, cells have access to oxygen almost instantly from ambient air through the membrane rather than through the media (Figure 1). This enables faster oxygen equilibration rates to be achieved at the cellular level. These fast rates of oxygen cycling therefore make this model particularly useful for protocols aimed at studying rapid changes in oxygenation or intermittent hypoxia, relevant to diseases such as cancer (Michiels et al., 2016), obstructive sleep apnea (Minoves et al., 2017; Martinez et al., 2019), cardiovascular disease and ischemia (Savla et al., 2018). 
A Traditional cell culture dish

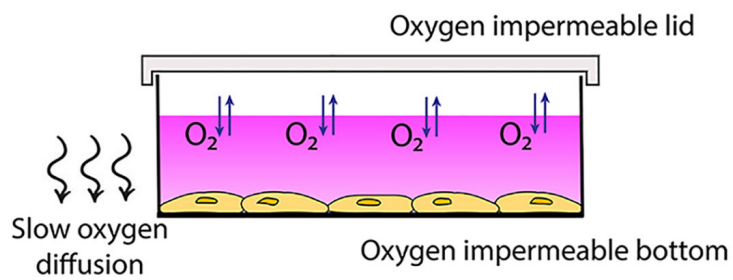

B Oxygen-permeable culture dish

Oxygen-permeable film

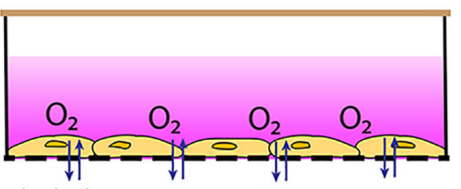

Oxygen-permeable membrane

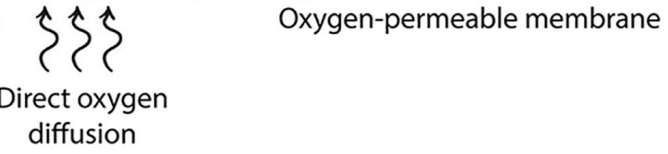

Figure 1. Traditional cell culture dish vs. oxygen-permeable culture dish. A. Traditional cell culture dishes are impermeable to oxygen so more time is required for oxygen to diffuse through the media to the cells. B. Plating cells onto oxygen-permeable membranes enables gas-phase oxygen to be sourced directly through the membrane.

\section{Materials and Reagents}

1. T75 flask

2. Pipette tips

3. $15 \mathrm{ml}$ sterile tube

4. $1.5 \mathrm{ml}$ microtubes

5. Oxygen-permeable culture plate (commercially available plates are shown in Table 1). This protocol uses a 2-well slide plate from Coy Lab Products

Table 1. List of commercially available oxygen-permeable membranes

\begin{tabular}{ll}
\hline Membrane & Manufacturer \\
\hline Fluorocarbon & Zell-Kontakt/Coy Lab Products (catalog number: 8602003) \\
\hline Polydimethylsiloxane (PDMS) & Specialty Silicone Products Inc. (catalog number: SSP- \\
& M823) \\
\hline Lumox & Sarstedt (catalog number: 94.6077.331) \\
\hline
\end{tabular}

6. AeraSeal ${ }^{\mathrm{TM}}$ film sterile (Sigma-Aldrich, catalog number: A9224-50EA)

7. Acrylic hypoxic chamber (Custom-made)

a. Clear Acrylic Round Cylinder Display Riser (Plymor, available through Amazon, USA)

b. $1 \mathrm{~cm}$ thick flat piece of acrylic (Plymor, available through Amazon, USA)

c. Tubing adaptors

d. Silicone grease

e. Epoxy or silicone glue

8. Blutack ${ }^{\mathrm{TM}}$

9. McCoy's modified media (Thermo Fisher, Gibco, catalog number: 36600-021)

10. DMEM/F12 media (Thermo Fisher, Gibco, catalog number: 11320-033) 
11. DMEM media (Thermo Fisher, Gibco, catalog number: 10313-039)

12. Foetal bovine serum (Thermo Fisher, Gibco, Australian FBS, catalog number: 26140-079)

13. Penicillin-Streptomycin (Thermo Fisher, Gibco, catalog number: 15070-063)

14. GlutaMAX (Thermo Fisher, Gibco, catalog number: 35050-061)

15. Dulbecco's phosphate buffered saline (Gibco, catalog number: 14190-144)

16. TrypLE (Thermo Fisher, Gibco, catalog number: 12605-028)

17. RNeasy Mini Kit (Qiagen, catalog number: 74104)

18. Tris- $\mathrm{HCl}$ (Sigma-Aldrich, catalog number: T3253)

19. $\mathrm{NaCl}$ (Omnipur, catalog number: 7710 )

20. EDTA (Sigma-Aldrich, catalog number: EDS)

21. $\mathrm{Na}_{4} \mathrm{P}_{2} \mathrm{O}_{7}$ (Chem Supply, catalog number: TA045)

22. SDS (Sigma-Aldrich, catalog number: L3771)

23. Sodium deoxycholate (Sigma-Aldrich, catalog number: D6750)

24. Triton X (VWR, catalog number: ICNA04807426)

25. Glycerol (Sigma-Aldrich, catalog number: G5516)

26. HEPES (Sigma-Aldrich, catalog number: H3375)

27. $\mathrm{KCl}$ (Sigma-Aldrich, catalog number: P9333)

28. Nonidet-P40 Substitute solution (Sigma-Aldrich, catalog number: 98379)

29. DTT (Pierce, Thermo Fisher Scientific, catalog number: 20291)

30. RIPA lysis buffer (see Recipes)

31. Cytoplasmic extraction buffer (see Recipes)

32. Nuclear extraction buffer (see Recipes)

\section{Equipment}

1. Laminar flow hood

2. Standard humidified cell culture incubator maintained at $5 \% \mathrm{CO}_{2}$

3. Water bath $\left(37^{\circ} \mathrm{C}\right)$

4. Hemocytometer

5. Microscope (Zeiss Primovert, $5 x$ and 10x objective lenses)

6. Centrifuge (Eppendorf, model: $5810 \mathrm{R}$ )

7. Gas blender (3 channel GB100, MCQ Instruments, version GB1E43120240)

8. $\mathrm{N}_{2}, \mathrm{CO}_{2}$ and $\mathrm{O}_{2}$ gas sources

9. Pre-mixed gas cannisters (BOC, catalog number: CCS15388E)

10. Tubing (provided by MCQ instruments, or can be purchased from Saint-Gobain T3)

11. Clamp stand

12. Profiling oxygen microsensor (PM-PSt7, PreSens) connected to a compact oxygen transmitter (OXY-1 ST, PreSens)

13. Microcentrifuge (Thermo Fisher Scientific, Heraeus Fresco $21\left[4{ }^{\circ} \mathrm{C}\right]$ ) 


\section{Software}

1. $M C Q$ Gas Mixture Creator PRO (MCQ Instruments, version 1)

2. PreSens Measurement Studio 2

3. Microsoft Excel

4. GraphPad Prism

\section{Procedure}

Any of the commercially available cultureware listed in Table 1 can be used in this cell culture system (thinner membranes will provide more rapid exchange with the ambient air). This procedure uses a 2well slide plate (Coy Lab Products). This procedure can also be conducted using any adherent cell line. We have used this model system on HCT116 colorectal cancer cells (Martinez et al., 2019), U251 glioblastoma cells, PC3 prostate cancer cells, and MDA-MB-231 and MCF7 breast cancer cells. Others have used a related system on endothelial cells, astrocytes and breast cancer cells (Minoves et al., 2017). In our experience, all cell lines successfully attached onto oxygen-permeable membrane without need for an extracellular matrix protein coating. Some cell lines may require extracellular matrix coating of the membrane to facilitate attachment.

Note: Ensure all cell culture handling is conducted using sterile technique in a laminar flow hood.

A. Prepare cell culture

1. Depending on the cell line, prepare the appropriate media supplemented with $1 \times$ GlutaMAX and $10 \%$ FBS, as listed in Table 2. (Optional: add $50 \mathrm{IU} / \mathrm{ml}$ penicillin and $50 \mu \mathrm{g} / \mathrm{ml}$ streptomycin to the media).

2. Pre-warm the media to $37^{\circ} \mathrm{C}$ in a water bath.

3. Seed cells onto a $T 75$ flask in $\sim 15 \mathrm{ml}$ pre-warmed media.

4. Culture cells in a standard humidified incubator maintained at $5 \% \mathrm{CO}_{2}$ at $37^{\circ} \mathrm{C}$.

Table 2. List of cell lines which have been tested in this model, the corresponding media, and the optimal seeding densities for a $6 \mathrm{~h}$ experiment

\begin{tabular}{lll}
\hline Cell line & $\begin{array}{l}\text { Media - supplement with 1x } \\
\text { GlutaMAX and 10\% FBS }\end{array}$ & $\begin{array}{l}\text { Approximate seeding densities for an } \\
18 \mathrm{~h} \text { experiment }\left(\mathrm{cells} / \mathrm{cm}^{2}\right)\end{array}$ \\
\hline HCT116 & McCoy's & $1.5 \times 10^{5}$ \\
\hline PC3 & DMEM/F12 & $5.0 \times 10^{4}$ \\
\hline U251 & DMEM & $5.0 \times 10^{4}$ \\
\hline MDA-MB-231 & DMEM & $7.0 \times 10^{5}$ \\
\hline MCF7 & DMEM & $2.0 \times 10^{5}$ \\
\hline
\end{tabular}

B. Seed cells onto oxygen-permeable membranes 
1. Aspirate the media from the T75 flask, wash cells with sterile PBS and dissociate with $2.5 \mathrm{ml}$ TrypLE dissociation reagent in the $37^{\circ} \mathrm{C}$ incubator for approximately 2 min (until cells detach from the flask).

2. Add $2.5 \mathrm{ml}$ pre-warmed media to the flask and gently pipet cells to ensure even suspension before counting.

3. Transfer cells to a $15 \mathrm{ml}$ sterile tube and count cells using a hemocytometer.

4. Centrifuge cells (using the Eppendorf $5810 \mathrm{R}$ ) at $300 \times \mathrm{g}$ for $5 \mathrm{~min}$ at room temperature.

5. Aspirate and discard the supernatant.

6. Add fresh, pre-warmed media to the pellet and resuspend cells, gently pipetting to ensure even suspension.

7. Prepare a 2-well oxygen-permeable slide plate and seed cells in $1.5 \mathrm{ml}$ media (see Figure 2A) at a density that enables cells to reach close to $100 \%$ confluency after $24 \mathrm{~h}$ incubation + the total duration in the treatment conditions (Optimal seeding densities for an $18 \mathrm{~h}$ experiment are shown in Table 2). For an $18 \mathrm{~h}$ experiment, the cells should be approximately $70-80 \%$ confluent before the dish is placed in the hypoxic chamber to be exposed to the treatment conditions (see Figure 2B).

8. Culture cells in a standard humidified incubator maintained at $5 \% \mathrm{CO}_{2}$ at $37^{\circ} \mathrm{C}$ for $24 \mathrm{~h}$.
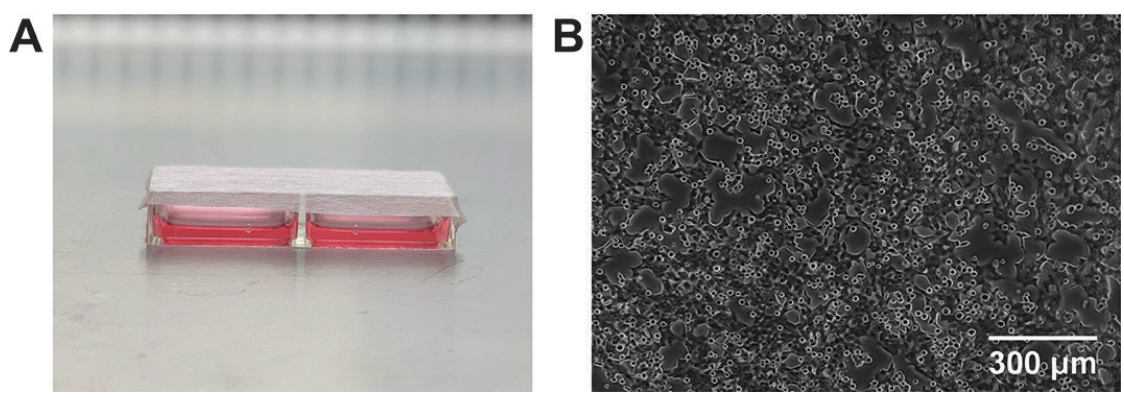

Figure 2. Oxygen-permeable dish containing adherent HCT116 cells. A. 2-well slide dish sealed with sterile AeraSeal film. B. Microscope image of HCT116 cells attached to the oxygenpermeable membrane $24 \mathrm{~h}$ after seeding.

C. Set up hypoxic chamber

This procedure uses a custom-made, cylindrical acrylic hypoxic chamber. To construct a simple customized hypoxic chamber, we purchased various sizes of preassembled Clear Acrylic Round Cylinder Display Risers (Plymor, available through Amazon, USA). The dimensions of this cylindershaped hypoxic chamber are: $7 \mathrm{~cm}$ in diameter (internal) and $3.5 \mathrm{~cm}$ in height, with a total volume of $140 \mathrm{~cm}^{3}$ (Figure 3B). Flat pieces of acrylic $(1 \mathrm{~cm}$ thick) can also be purchased from Plymor for use as the lid. The acrylic can be cut to a diameter slightly bigger than the diameter of the chamber. The lid of the chamber used in this protocol has a diameter of $8 \mathrm{~cm}$ (Figure 3A).

To ensure a tight seal, a groove can be sculpted into the underside of the lid so that it fits snugly onto the cylinder (see Figure 3C). Alternatively, the addition of $\sim 200 \mu \mathrm{l}-500 \mu \mathrm{l}$ of silicone grease on the rim of the hypoxic chamber at the start of the experiment should be enough to hold the lid in 
place to ensure an airtight fit. A weight can be added on top of the lid to ensure the lid stays in place (Figure 4D).

The hypoxic chamber should have inlet and outlet holes for flowing gases (Figure 3 and 4), which can be drilled in the lid. Tubing adaptors (see Figures $4 \mathrm{~A}$ and $4 \mathrm{~B}$ ) can be purchased from the local hardware store and placed in the holes drilled in the lid $(\sim 1 \mathrm{~cm}$ in diameter). The adaptors can be secured in place using epoxy or silicone glue.

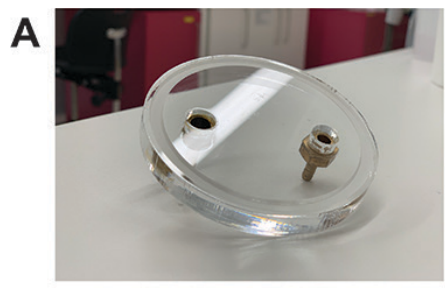

B

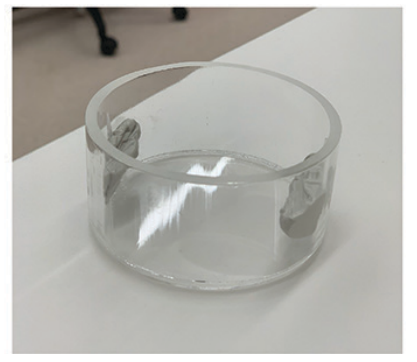

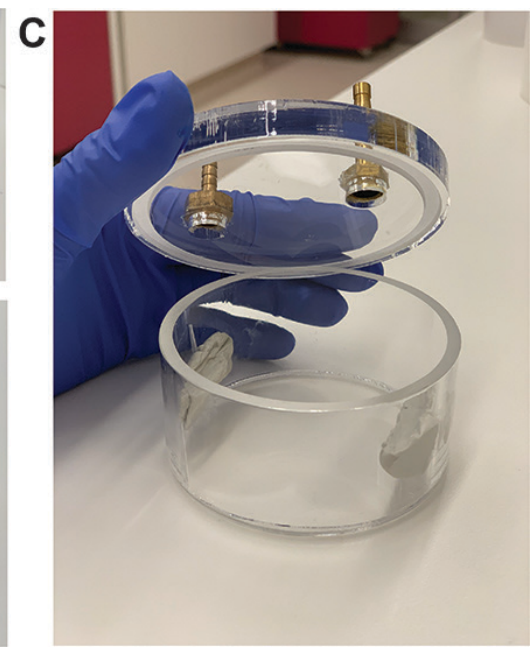

Figure 3. Construction of a hypoxic chamber. A. The lid of the chamber is a flat piece of acrylic (purchased from Plymor, $1 \mathrm{~cm}$ thick) with a groove sculpted about $1 \mathrm{~mm}$ into the underside of the lid. The lid also contains two holes $(1 \mathrm{~cm}$ in diameter) as an inlet and an outlet for flowing gases. Tubing adapters can be secured into these holes using epoxy or silicone glue. B. The hypoxic chamber is an acrylic cylinder with a flat bottom (purchased from Plymor). The cylinder is $7 \mathrm{~cm}$ in diameter, $3.5 \mathrm{~cm}$ in height and has a total volume of $140 \mathrm{~cm}^{3}$. C. The groove in the lid of the chamber nicely slots into the rim of the cylindrical hypoxic chamber to ensure an airtight fit.

1. After $24 \mathrm{~h}$ incubation in the incubator, discard the media and replace with $1.5 \mathrm{ml}$ pre-warmed media supplemented with $0.5 \%$ FBS.

2. Seal the wells with sterile AeraSeal ${ }^{\mathrm{TM}}$ film (see Figure $2 \mathrm{~A}$ ).

3. Place the slide plate within a hypoxic chamber, ensuring that the underside of the oxygenpermeable membrane is elevated off the floor of the chamber.

Note: Use pipette tips and Blutack ${ }^{T M}$ to prop the plate up and use a spirit level to ensure the plate is level with the floor-see Figures $4 A-4 C$.

4. Place the lid on top of the chamber, ensuring that the inlet is positioned away from the culture plate to prevent gas from flowing directly onto cells (Figure 4A).

5. Immerse the chambers in a $37^{\circ} \mathrm{C}$ water bath within the $\mathrm{CO}_{2}$ incubator. The warm water bath assists in maintaining the chamber walls and internal gases at $37^{\circ} \mathrm{C}$.

Note: If the chamber is prone to floating, use a weight to hold down the chamber in the water 

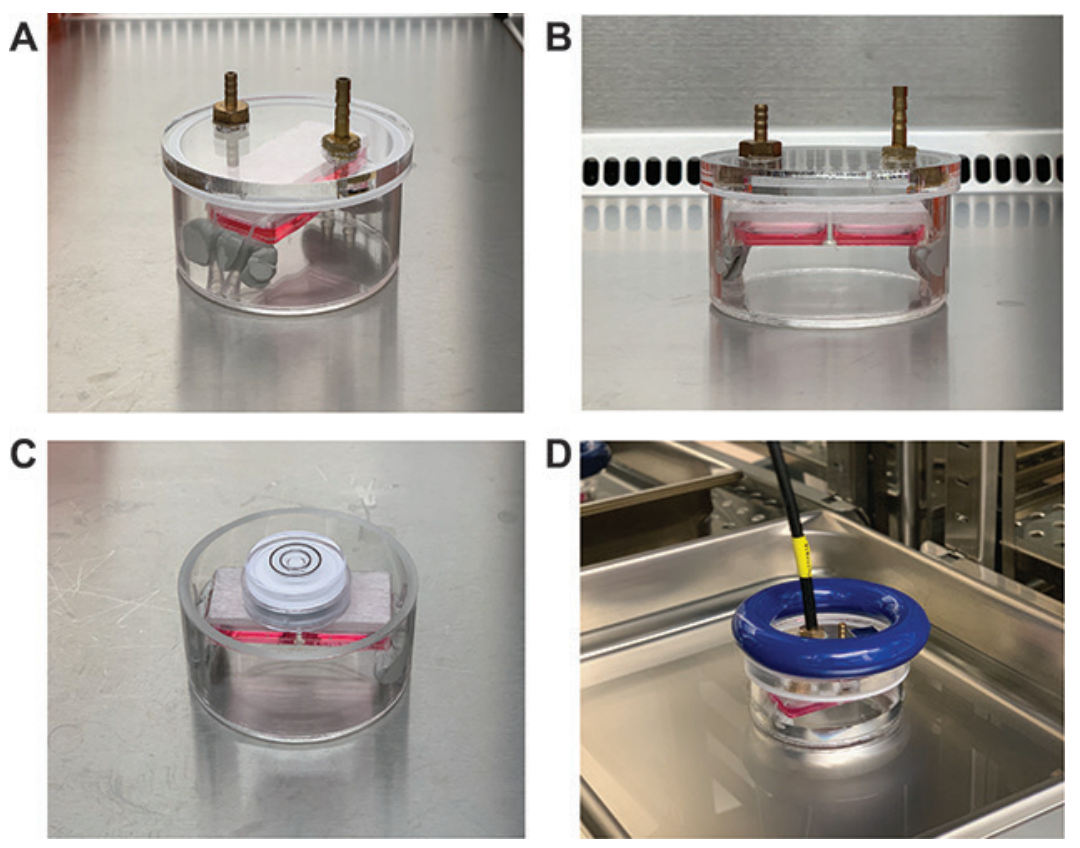

Figure 4. Hypoxic chamber setup. A. Top view of the hypoxic chamber containing the 2-well slide plate. The 2-well plate is elevated by Blutack ${ }^{\mathrm{TM}}$ to the inner walls of the chamber. The lid of the chamber consists of an inlet hole and an outlet hole for flowing gases. The inlet hole is positioned away from the culture dish. B. Front view of the hypoxic chamber containing the 2well slide plate. C. A spirit level placed on top of the plate to ensure that it is level. D. Hypoxic chamber containing the plate, immersed in a water bath within a $37^{\circ} \mathrm{C}, \mathrm{CO}_{2}$ incubator. The input tube is connected to the hypoxic chamber via the inlet. For input tubing, use the tubing provided by MCQ for the gas mixer. Saint-Gobain T3 tubing is also acceptable. The chamber is held down by a weight.

D. Define gas compositions to mimic tissue oxygenation (Examples/suggestions)

1. Defining normoxia

Oxygen concentrations to represent physiological normoxia may vary depending on the tissue of interest. There have been studies that have measured oxygenation in various tissues in vivo using an oxygen sensor (see Table 1 in [Hunyor and Cook, 2018]). Estimations can therefore be made based on these measurements. Alternatively, a good starting point is to use an oxygen concentration that represents oxygenation of cells located close to major blood vessels $(\sim 90$ $\mathrm{mmHg}$ or $12 \% \mathrm{v} / \mathrm{v})$.

2. Defining hypoxia

Hypoxic concentrations should be set according to the type of disease being modeled. In tumors, oxygen values can range from 2 to $15 \mathrm{mmHg}$, depending on the size, location and tissue type. $4 \mathrm{mmHg}$ is a good starting point to reflect severe hypoxia in tumors.

3. Defining intermittent hypoxia 
Protocols of intermittent hypoxia will also depend on the type of disease being modeled. This procedure has been used in a previous study that modeled obstructive sleep apnea in tumors (Martinez et al., 2019). Oxygen concentrations for intermittent hypoxia were based on measurements taken in a mouse tumor (subcutaneous melanoma) model of obstructive sleep apnea. Oxygen fluctuations in the tumor alternated between $\sim 5 \mathrm{mmHg}(0.6 \% \mathrm{v} / \mathrm{v})$ to $\sim 50 \mathrm{mmHg}$ (7\% v/v) (Almendros et al., 2013), so protocols of oxygen cycling were modified to produce fluctuations between 5 and $50 \mathrm{mmHg}$ in the pericellular media (Martinez et al., 2019) (see Figure $6 G)$.

E. Expose cells to the desired mixed gases

1. For exposures to one oxygen condition (i.e., continuous normoxia or continuous hypoxia), the inlet of the chamber can be connected to a gas canister pre-mixed to the desired gas composition (If this step was used, skip to Procedure G).

2. Alternatively, the inlet of the chamber can be connected to a gas blender connected to $\mathrm{N}_{2}, \mathrm{O}_{2}$ and $\mathrm{CO}_{2}$ gas sources. This step is particularly useful for changing oxygen conditions over time (i.e., for modeling intermittent hypoxia). See Procedure $F$ for instructions on how to program the gas blender.

F. Program the gas blender to the desired gas composition

1. Turn on the MCQ Gas Blender box.

2. Open the MCQ Gas Mixture Creator PRO software (Figure 5).

3. Select 'Edit Program'.

4. Enter the desired percentage (\%) fractions of each gas component on the corresponding channel $(\mathrm{CH})$ (See Figure $5 \mathrm{~B})$. For example:

a. To program for physiological normoxia at $12 \% \mathrm{O}_{2}(\mathrm{v} / \mathrm{v})$ to mimic well-oxygenated cells near major blood vessels, set values for each channel to: $\mathrm{N}_{2}(\mathrm{CH} 1)=83 \%, \mathrm{O}_{2}(\mathrm{CH} 2)=12 \%, \mathrm{CO}_{2}$ $(\mathrm{CH} 3)=5 \%$ (buffer).

b. To program for hypoxia at $0.5 \% \mathrm{O}_{2}(\mathrm{v} / \mathrm{v})$ to mimic severe tumor hypoxia, set values for each channel to: $\mathrm{N}_{2}(\mathrm{CH} 1)=94.5 \%, \mathrm{O}_{2}(\mathrm{CH} 2)=0.5 \%, \mathrm{CO}_{2}(\mathrm{CH} 3)=5 \%$ (buffer).

c. To program for intermittent hypoxia, set values in one line to: $\mathrm{N}_{2}(\mathrm{CH} 1)=87 \%, \mathrm{O}_{2}(\mathrm{CH} 2)=$ $8 \%, \mathrm{CO}_{2}(\mathrm{CH} 3)=5 \%$. Select add line and set values of the second line to: $\mathrm{N}_{2}(\mathrm{CH} 1)=95 \%$, $\mathrm{O}_{2}(\mathrm{CH} 2)=0 \%, \mathrm{CO}_{2}(\mathrm{CH} 3)=5 \%$ (buffer), etc.

5. Set 'FLOW' (SCCM; equivalent to $\mathrm{ml} / \mathrm{min}$ ) to the desired flow rate.

6. Set 'TIME WORK' to the desired duration of exposure in each condition.

7. Save the protocol.

8. Select 'OK'.

9. Select 'Run program' to begin exposure to the programmed oxygen conditions.

Note: When modeling intermittent hypoxia, 'TIME WORK'duration may need to be extended to allow for oxygen concentrations in the pericellular media to reach the desired level. Oxygen 
concentrations in the pericellular media can be measured using an oxygen electrode (see Procedure G).
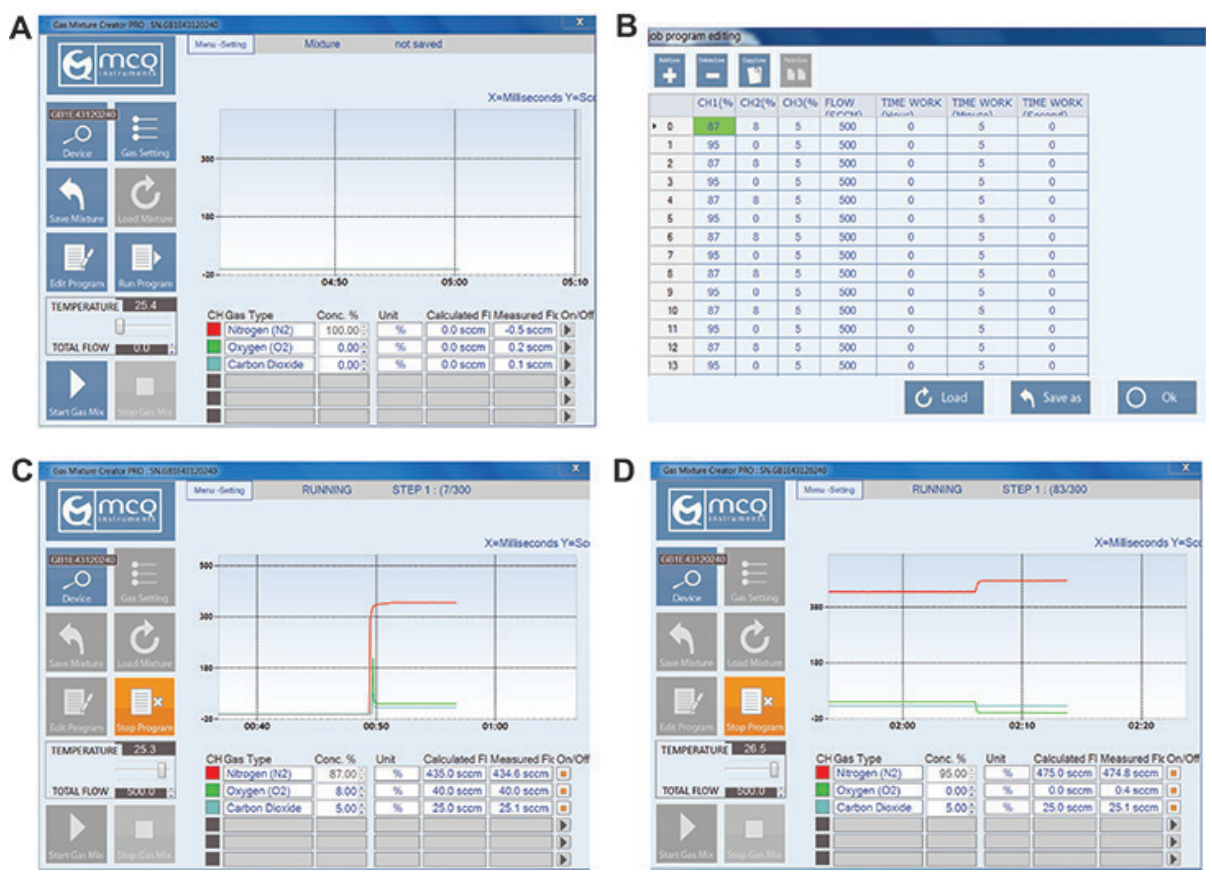

Figure 5. Programming gas compositions using the MCQ Gas Mixture Creator PRO software. A. Opening page of MCQ Gas Mixture Creator PRO software. B. The job program editing page (after selecting 'Edit Program'). To model intermittent hypoxia, $\mathrm{N}_{2}(\mathrm{CH} 1)$ was set to $87 \%$ or $95 \%$ per line, $\mathrm{O}_{2}(\mathrm{CH} 2)$ was set to $8 \%$ or $0 \%$ per line, and $\mathrm{CO}_{2}(\mathrm{CH} 3)$ was set to $5 \%$. Flow rate was set to $500 \mathrm{SCCM}$ (equivalent to $\mathrm{ml} / \mathrm{min}$ ). Time work was set to $5 \mathrm{~min}$ per line. C. The running program after selecting 'Run Program', starting with $87 \% \mathrm{~N}_{2}, 8 \% \mathrm{O}_{2}$, and $5 \% \mathrm{CO}_{2}$. D. The running program when oxygen conditions alternate to $95 \% \mathrm{~N}_{2}, 0 \% \mathrm{O}_{2}$, and $5 \% \mathrm{CO}_{2}$.

G. Measure oxygen concentrations (to verify oxygen levels in the pericellular media) Preparation: drill an extra hole in the lid of the chamber to enable insertion of an oxygen or temperature probe. When not in use, seal the hole with foil adhesive. The size of the hole drilled should be appropriate for the size of the oxygen probe being used, which is brand and model dependent (typically $5 \mathrm{~mm}-1 \mathrm{~cm}$ in diameter).

1. Insert the needle of the oxygen sensor through the hole in the lid of the chamber, through the AeraSeal film and twist the top of the sensor to extract the oxygen-sensing tip (see Figure 6A).

2. Use a clamp stand to hold the electrode in place.

3. Open the PreSens Measurement Studio 2 software.

4. Select the OXY-1 channel.

5. Select the 'Measurements' tab.

6. Select 'New'. Name the new measurement file.

7. Click on the measurement file and select 'Assign to'.

8. Select the 'Live View' tab and click 'Start' to begin taking measurements. 
9. Export data Excel or GraphPad Prism and graph measurements (see Figures 6B-6G for examples).

Note: Oxygen equilibration in the air is much faster than through media, so it is also useful to take initial measurements in the air within the chamber to ensure the oxygen probe is working correctly. Oxygen concentrations will also vary depending on the placement of the oxygen probe (oxygen concentrations at the pericellular level will not be accurate if the probe is not placed directly on the membrane (cell side)). The volume of the culture media added to the well will also affect oxygen concentrations (Minoves et al., 2017). Take care when handling the oxygen probe to prevent damage of the sensor and piercing of the membrane of the culture dish.

A

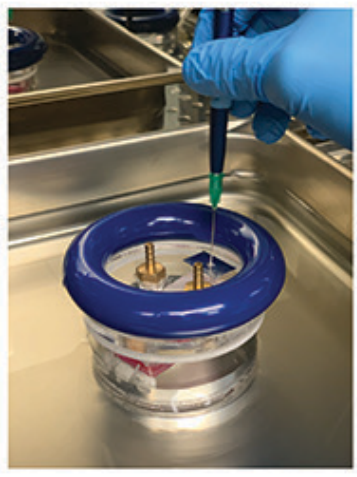

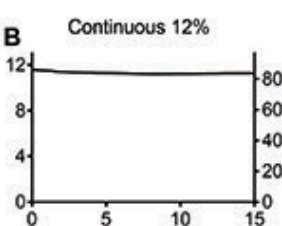

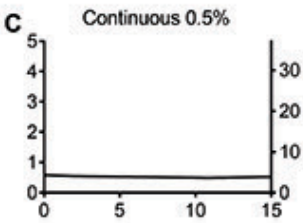

$\frac{2}{3}$

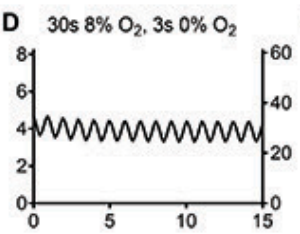

E $1 \min 8 \% \mathrm{O}_{2}, 1 \min 0 \% \mathrm{O}_{2}$

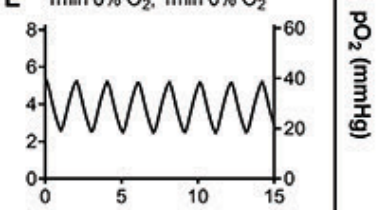

F $3 \min 8 \% \mathrm{O}_{2}, 3 \min 0 \% \mathrm{O}_{2}$
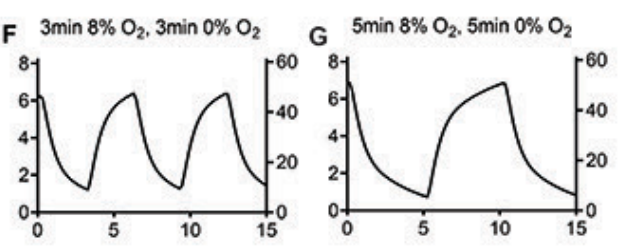

Time (min)

Figure 6. Oxygen measurements in the pericellular media using the PreSens Oxygen Microsensor (graphed on GraphPad Prism). A. Insertion of the needle of the oxygen probe through the hole in the lid of the hypoxic chamber. B. Exposure to $12 \% \mathrm{O}_{2}$ continuously, $\mathrm{C}$. Exposure to $0.5 \% \mathrm{O}_{2}$ continuously, D. Exposure to $30 \mathrm{~s}$ of $8 \% \mathrm{O}_{2}$ followed by $30 \mathrm{~s}$ of $0 \% \mathrm{O}_{2}$, E. Exposure to $1 \mathrm{~min}$ of $8 \% \mathrm{O}_{2}$ followed by $1 \mathrm{~min}$ of $0 \% \mathrm{O}_{2}$, E. Exposure to $3 \mathrm{~min}$ of $8 \% \mathrm{O}_{2}$ followed by $3 \mathrm{~min}$ of $0 \% \mathrm{O}_{2}$, and $\mathrm{G}$. Exposure to $5 \mathrm{~min}$ of $8 \% \mathrm{O}_{2}$ followed by $5 \mathrm{~min}$ of $0 \% \mathrm{O}_{2}$. D-G. Time in each condition needed to be extended to $5 \mathrm{~min}$ in order for pericellular levels to reach the desired oxygen tension of $50 \mathrm{mmHg}$ at the peak of cycles and $5 \mathrm{mmHg}$ at the nadir or trough of cycles. Different oxygen concentrations can be modeled (see [Minoves et al., 2017]) depending on oxygen requirements for the tissue of interest.

H. Harvest cells and analyze expression

Cells can be analyzed by microscopy (1), by protein expression (2) or by mRNA expression (3).

1. Microscopy

Commercially available oxygen-permeable dishes were originally developed for imaging 
purposes. Cells can be probed with fluorescent dyes or transfected with protein-specific green fluorescent proteins (GFPs) and analyzed by fluorescence microscopy.

2. Protein expression

Cells can be harvested to extract total protein by scraping cells in RIPA lysis buffer or harvested to separate nuclear and cytoplasmic proteins in the following procedure:

a. Add $300 \mu \mathrm{l}$ ice-cold cytoplasmic extraction buffer to each well of the culture plate.

b. Scrape cells well and transfer the lysate to a pre-chilled $1.5 \mathrm{ml}$ microtube.

c. Vortex the microtube for $15 \mathrm{~s}$ and incubate on ice for $5 \mathrm{~min}$.

d. Centrifuge for $5 \mathrm{~min}$ at $4{ }^{\circ} \mathrm{C}$ (using the Fresco 21 at 21,100 $\mathrm{xg}$ ).

e. Aspirate the supernatant (cytoplasmic protein extract) and transfer to a pre-chilled $1.5 \mathrm{ml}$ microtube. Place the microtube on ice or store at $-30^{\circ} \mathrm{C}$ until use.

f. Resuspend the pellet in $100 \mu$ ice-cold nuclear extraction buffer.

g. Vortex the microtube for $15 \mathrm{~s}$ and incubate on ice for $10 \mathrm{~min}$. Repeat Step H2c more times for a total duration of $40 \mathrm{~min}$.

h. Centrifuge for $10 \mathrm{~min}$ at $4{ }^{\circ} \mathrm{C}$ (using the Fresco 21 at $21,100 \times \mathrm{g}$ ).

i. Aspirate the supernatant (nuclear protein extract) and transfer to a pre-chilled $1.5 \mathrm{ml}$ microtube. Place the microtube on ice or store at $-30^{\circ} \mathrm{C}$ until use. Discard the pellet.

j. Protein expression can then be analyzed by western blotting.

3. mRNA expression

Cells can be harvested by scraping to extract total RNA. Use the RNeasy mini kit (Qiagen) and follow procedure according to the manufacturer's instructions. Convert purified mRNA to cDNA by reverse transcription. Quantify expression by qPCR.

\section{$\underline{\text { Recipes }}$}

1. RIPA lysis buffer

$10 \mathrm{mM}$ Tris $\mathrm{HCl} \mathrm{pH} 7.5$

$100 \mathrm{Mm} \mathrm{NaCl}$

1 mM EDTA

$1 \mathrm{mM} \mathrm{Na}_{4} \mathrm{P}_{2} \mathrm{O}_{7}$

$0.1 \%$ SDS

$0.5 \%$ Sodium deoxycholate

$1 \%$ Triton $X$

$10 \%$ Glycerol

2. Cytoplasmic extraction buffer

10 mM HEPES pH 7.5

$10 \mathrm{mM} \mathrm{KCl}$

$0.5 \mathrm{mM}$ EDTA

$0.5 \%$ Nonidet- 40 
$1 \mathrm{mM} \mathrm{DTT}$

3. Nuclear extraction buffer

20 mM HEPES pH 7.5

$400 \mathrm{mM} \mathrm{NaCl}$

1 mM EDTA

$1 \mathrm{mM}$ DTT

\section{Acknowledgments}

KMC is funded by a Cancer Institute NSW Early Career Research Fellowship, a University of Sydney Fellowship and a Sydney Medical Foundation grant. She has also received funding from the AMP Foundation. This protocol has been modified and adapted from (Minoves et al., 2017) and (Martinez et al., 2019).

\section{Competing interests}

The authors have no competing interests to declare.

\section{References}

1. Allen, C. B., Schneider, B. K. and White, C. W. (2001). Limitations to oxygen diffusion and equilibration in in vitro cell exposure systems in hyperoxia and hypoxia. Am J Physiol Lung Cell Mol Physiol 281(4): L1021-L1027.

2. Almendros, I., Montserrat, J. M., Torres, M., Dalmases, M., Cabanas, M. L., Campos-Rodriguez, F., Navajas, D. and Farre, R. (2013). Intermittent hypoxia increases melanoma metastasis to the lung in a mouse model of sleep apnea. Respir Physiol Neurobiol 186(3): 303-307.

3. Bordt, E. A. (2018). The importance of controlling in vitro oxygen tension to accurately model in vivo neurophysiology. Neurotoxicology 66: 213-220.

4. Byrne, M. B., Leslie, M. T., Gaskins, H. R. and Kenis, P. J. A. (2014). Methods to study the tumor microenvironment under controlled oxygen conditions. Trends in Biotechnol 32(11): 556563.

5. Carreau, A., El Hafny-Rahbi, B., Matejuk, A., Grillon, C. and Kieda, C. (2011). Why is the partial oxygen pressure of human tissues a crucial parameter? Small molecules and hypoxia. $J$ Cell Mol Med 15(6): 1239-1253.

6. Cook, K. M. and Figg, W. D. (2010). Angiogenesis inhibitors: current strategies and future prospects. CA Cancer J Clin 60(4): 222-243.

7. Cook, K. M., Hilton, S. T., Mecinović, J., Motherwell, W. B., Figg, W. D. and Schofield, C. J. (2009). Epidithiodiketopiperazines block the interaction between hypoxia-inducible factor-1 $\alpha$ (HIF-1 $\alpha$ ) and $\mathrm{p} 300$ by a zinc ejection mechanism. J Biol Chem 284(39): 26831-26838. 
8. Dunwoodie, S. L. (2009). The role of hypoxia in development of the mammalian embryo. Dev Cell 17(6): 755-773.

9. Hoffman, W. E., Charbel, F. T., Gonzalez-Portillo, G. and Ausman, J. I. (1999). Measurement of ischemia by changes in tissue oxygen, carbon dioxide, and pH. Surg Neurol 51(6): 654-658.

10. Holmquist-Mengelbier, L., Fredlund, E., Löfstedt, T., Noguera, R., Navarro, S., Nilsson, H., Pietras, A., Vallon-Christersson, J., Borg, A., Gradin, K., Poellinger, L. and Påhlman, S. (2006). Recruitment of HIF-1 $\alpha$ and HIF-2 $\alpha$ to common target genes is differentially regulated in neuroblastoma: HIF-2 $\alpha$ promotes an aggressive phenotype. Cancer Cell 10(5): 413-423.

11. Hunyor, I. and Cook, K. M. (2018). Models of intermittent hypoxia and obstructive sleep apnea: molecular pathways and their contribution to cancer. Am J Physiol Regul Integr Comp Physiol. 315(4): R669-R687.

12. Lin, Q., Cong, X. and Yun, Z. (2011). Differential hypoxic regulation of hypoxia-inducible factors $1 \alpha$ and 2a. Mol Cancer Res 9(6): 757-765.

13. Martinez, C. A., Kerr, B., Jin, C., Cistulli, P. A. and Cook, K. M. (2019). Obstructive sleep apnea activates HIF-1 in a hypoxia dose-dependent manner in HCT116 colorectal carcinoma cells. Int J Mol Sci 20(2). pii: E445.

14. Michiels, C., Tellier, C. and Feron, O. (2016). Cycling hypoxia: A key feature of the tumor microenvironment. Biochim Biophys Acta 1866(1): 76-86.

15. Minoves, M., Morand, J., Perriot, F., Chatard, M., Gonthier, B., Lemarié, E., Menut, J. B., Polak, J., Pépin, J. L., Godin-Ribuot, D. and Briançon-Marjollet, A. (2017). An innovative intermittent hypoxia model for cell cultures allowing fast $\mathrm{Po} 2$ oscillations with minimal gas consumption. $A m$ J Physiol cell Physiol 313(4): C460-C468.

16. Palazon, A., Goldrath, A. W., Nizet, V. and Johnson, R. S. (2014). HIF transcription factors, inflammation, and immunity. Immunity 41(4): 518-528.

17. Place, T. L., Domann, F. E. and Case, A. J. (2017). Limitations of oxygen delivery to cells in culture: An underappreciated problem in basic and translational research. Free Radic Biol Med 113: 311-322.

18. Savla, J. J., Levine, B. D. and Sadek, H. A. (2018). The effect of hypoxia on cardiovascular disease: friend or foe? High Alt Med Biol 19(2): 124-130.

19. Thangarajah, H., Vial, I. N., Grogan, R. H., Yao, D., Shi, Y., Januszyk, M., Galiano, R. D., Chang, E. I., Galvez, M. G., Glotzbach, J. P., Wong, V. W., Brownlee, M. and Gurtner, G. C. (2010). HIF-1a dysfunction in diabetes. Cell Cycle 9(1): 75-79.

20. Wenger, R. H., Kurtcuoglu, V., Scholz, C. C., Marti, H. H. and Hoogewijs, D. (2015). Frequently asked questions in hypoxia research. Hypoxia (Auckl) 3: 35-43.

21. Wu, D. and Yotnda, P. (2011). Induction and testing of hypoxia in cell culture. J Vis Exp (54). pii: 2899. 